\title{
Comparative Study of Long Span Beams Built up with an Ordinary Structural Steel at High Temperatures
}

\author{
In-Kyu Kwon \\ Department of Fire Protection Engineering, Kangwon National University, Samcheok, Korea
}

\begin{abstract}
Fire resistance for steel framed buildings is very important not only to guard lives that live and visit but to sustain the structural stability to prevent falling down. To evaluate and compare the fire resistance of long span beams built with ordinary structural steels, fire engineering method using mechanical properties at high temperatures and a heat transfer theory and a stress analysis was applied. Long span beams made of SS 400, SM 400 showed similar results in aspects of maximum load capacities and deflections during high temperatures.
\end{abstract}

Keywords-component; ordinary structural steel; fire resistance; long span beam; structural stability

\section{INTRODUCTION}

Structural steel has been used from 1800's and it regarded as a good structural material in high-rise buildings. Especially, the structural properties such as high strength in tensile and compressive and elastic modulus make the buildings robust than other structural ones. And the structural design method has been developed with the performance of the structural steel. However, the buildings built with the structural steel didn't show robust performance when those are engulfed in a fire. Therefore, the building regulation and building codes require fire resistance for each major structural element with time scale. When the fire resistance is mentioned in criterion, there are two ways. The first one is based on building regulation or standard. This is known as a prescriptive method and all most of countries utilize the one. The other is known as a fire engineering method and a world trend to evaluate the performance of fire resistance for each structural member and frames. In my country, the fire engineering design is not mentioned in building regulation so that in the building acceptance process the fire resistance has to be used from building regulation or verified from building authority [1]. However, to utilize the fire engineering technique into building industries so many effects are ongoing. In this paper to know the exact performance of structural behavior of long span beams built with structural steels such as SS 400, SM 400, an analytical method is used.

\section{An AnAlytical Method for Fire ResistanCE}

\section{A. Analytical Process for Fire Resistance}

The process to know the exact fire resistance is that at first to make the specimen and put it into fire furnace and keep it until the member should be sustained the standard fire duration with loading. This is a hard work and turned it into un-rational method when the fire resistance of structural member is needed in aspects of technical and economical. Because the analytical knowledge has been accumulated and the fire tests have been done so many times and it showed similar results from various fire test facilities and the results can be shared. In this study, mechanical properties and thermal ones at high temperatures are used when the fire engineering method is done and a heat transfer theory and a stress analysis are used together.

\section{B. Analysis Plan}

Long span beam having 4100, 4400, 4700, and 5000mm in length are applied for these lengths are very popular in real steel framed building. But performance of the beams in fire situation is not found easily because the fire test facility only has an international standard size. One example, in my country a fire facility has $4000 \mathrm{~mm}$ in length. Therefore, as the length of beam is increased, to know the performance of fire resistance is so hard. In this study, to know the performance of the long span beam, a simple and a fixed boundary are applied. These two boundary conditions are very common in steel framed building and it is very important to compare the results from the differences of boundary condition. The table 1 shows the plan of analytical parameters for long span beam.

TABLE I. ANALYSIS PARAMETERS

\begin{tabular}{|c|c|}
\hline SECTION & $\mathrm{H}-400 \times 200 \times 8 \times 13$, Section area $\left(84.12 \mathrm{~cm}^{2}\right)$ \\
\hline SUPPORT CONDITIONS & Simple beam and fixed beam \\
\hline SPAN OF BEAM(MM) & $4100,4400,4700,5000$ \\
\hline FIRE CURVE & Standard fire curve, KS F 2257-1,6 \\
\hline
\end{tabular}

Mechanical properties of SS 400 and SM 400 such as yield strength and elastic modulus to represent structural behaviors are shown in Table 2 and Table 3. The mechanical properties were derived from Korean standards $[2,3]$ 
TABLE II. MECHANICAL PROPERTIES OF SS 400 AT HIGH TEMPERATURES

\begin{tabular}{|c|c|c|}
\hline PROPERTIES & TEMPERATURES & REGRESSION EQUATION \\
\hline \multirow{2}{*}{ Yield strength } & $\mathrm{T} \subseteq 200^{\circ} \mathrm{C}$ & Cold value (240 MPa) \\
\cline { 2 - 3 } & $200^{\circ} \mathrm{C}<\mathrm{T} \subseteq 900$ & $-0.32 \mathrm{~T}+303.21$ \\
\hline \multirow{2}{*}{ Elastic modulus } & $\mathrm{T} \subseteq 100^{\circ} \mathrm{C}$ & Cold value (210GPa) \\
\cline { 2 - 3 } & $100^{\circ} \mathrm{C}<\mathrm{T} \subseteq 900$ & $-0.22 \mathrm{~T}+232.16$ \\
\hline
\end{tabular}

TABLE III. MECHANICAL PROPERTIES OF SM 400 AT HIGH TEMPERATURES

\begin{tabular}{|c|c|c|}
\hline PROPERTIES & TEMPERATURES & REGRESSION EOUATION \\
\hline \multirow{3}{*}{ Yield strength } & $\mathrm{T} \subseteq 200^{\circ} \mathrm{C}$ & Cold value (240 MPa) \\
\cline { 2 - 3 } & $200^{\circ} \mathrm{C}<\mathrm{T} \subseteq 900$ & $-0.29 \mathrm{~T}+293.44$ \\
\hline \multirow{3}{*}{ Elastic modulus } & $\mathrm{T} \subseteq 200^{\circ} \mathrm{C}$ & Cold value (210GPa) \\
\cline { 2 - 3 } & $200^{\circ} \mathrm{C}<\mathrm{T} \subseteq 900$ & $-0.26 \mathrm{~T}+261.18$ \\
\hline
\end{tabular}

\section{RESULTS OF ANALYSIS}

\section{A. Calculations}

Typical length for beam is $4100 \mathrm{~mm}$ when the beam is required to be tested in furnace. This length means the standard length in horizontal furnace and most structural beams are tested with this length in Korea. When the fire resistance performance of the beam is evaluated using an engineering method, the maximum moment is derived at first stage from two boundary conditions. The second process is that to calculate the maximum load and then deflection calculation is conducted.

The maximum moment and maximum load calculated are shown in Table 4. In the table as the length of beams are longer, the higher maximum moment but maximum loads are going to decrease.

TABLE IV. MAXIMUM MOMENTS AND MAXIMUM LOADS VERSUS BEAM LENGTHS

\begin{tabular}{|c|c|c|c|c|c|c|}
\hline \multirow{2}{*}{ SORTS } & \multirow{2}{*}{\multicolumn{2}{|c|}{ FACTORS }} & \multicolumn{4}{|c|}{ LENGTH(MM) } \\
\hline & & & 4100 & 4400 & 4700 & 5000 \\
\hline \multirow{3}{*}{$\begin{array}{c}\text { Simple } \\
\text { beam }\end{array}$} & \multirow{2}{*}{$\begin{array}{c}1 \\
\text { Point }\end{array}$} & $\begin{array}{l}\text { Maximum } \\
\text { moment }\end{array}$ & $2.46 \mathrm{P}$ & $2.76 \mathrm{P}$ & $3.06 \mathrm{P}$ & $3.36 \mathrm{P}$ \\
\hline & & $\begin{array}{l}\text { Value } \\
(\mathrm{MPa})\end{array}$ & 69.02 & 57.32 & 48.40 & 41.44 \\
\hline & $\begin{array}{c}4 \\
\text { Points }\end{array}$ & Value(MPa) & 276.09 & 229.30 & 193.62 & 165.75 \\
\hline \multirow{3}{*}{$\begin{array}{l}\text { Fixed } \\
\text { beam }\end{array}$} & \multirow{2}{*}{$\begin{array}{c}1 \\
\text { Point }\end{array}$} & $\begin{array}{c}\text { Maximum } \\
\text { moment }\end{array}$ & $1.63 \mathrm{P}$ & $1.83 \mathrm{P}$ & $1.99 \mathrm{P}$ & $2.16 \mathrm{P}$ \\
\hline & & Value(MPa) & 104.17 & 86.46 & 74.43 & 64.46 \\
\hline & $\begin{array}{c}4 \\
\text { Point }\end{array}$ & Value(MPa) & 416.67 & 345.83 & 297.72 & 257.83 \\
\hline
\end{tabular}

\section{B. Results and Discussions}

Steel surface temperatures of SS 400 and SM 400 are going to increase when the beams are exposed to a standard fire curve and the results are shown in Figure 1, respectively. The surface temperature of SM 400 showed a little lower than that of SS 400 during 20 minutes. It was regarded that a heat conductivities of SM 400 is lower than that of SS 400 .

The maximum loads according to structural steels and boundary condition are shown in Figure 2 to Figure 5. In the figure, the maximum loads are going to down with increasing surface temperatures. In case of fixed beams showed higher values of maximum load than those of simple beams. At here, it is clear that a fixed boundary condition is to carry much more load than that of simple beam. At each boundary condition, the decreasing patterns are very close but as the length beams are longer, the reduction ratios are diminished.

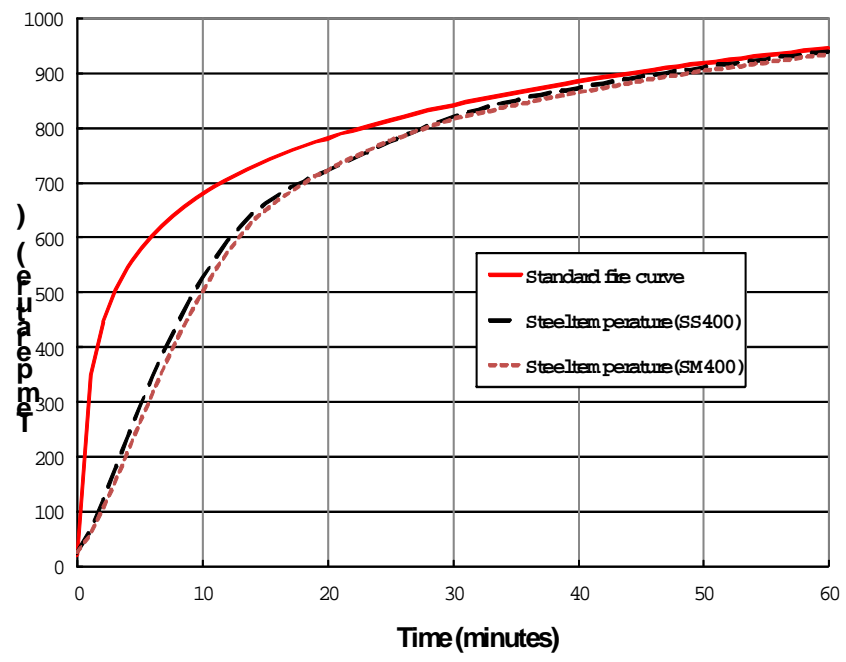

FIGURE I. STEEL SURFACE TEMEPRATURES VERSUS ELASPED TIMES

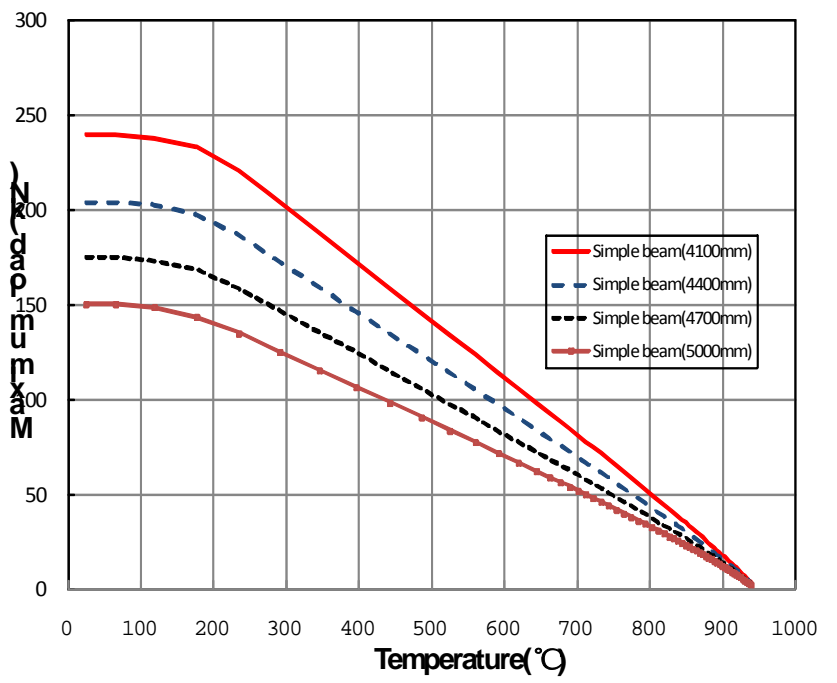

FIGURE II. MAXIMUM LOADS CHANGES ACCORDING TO SURFACE TEMPAERATURES(SIMPLE BEAM, SS 400) 


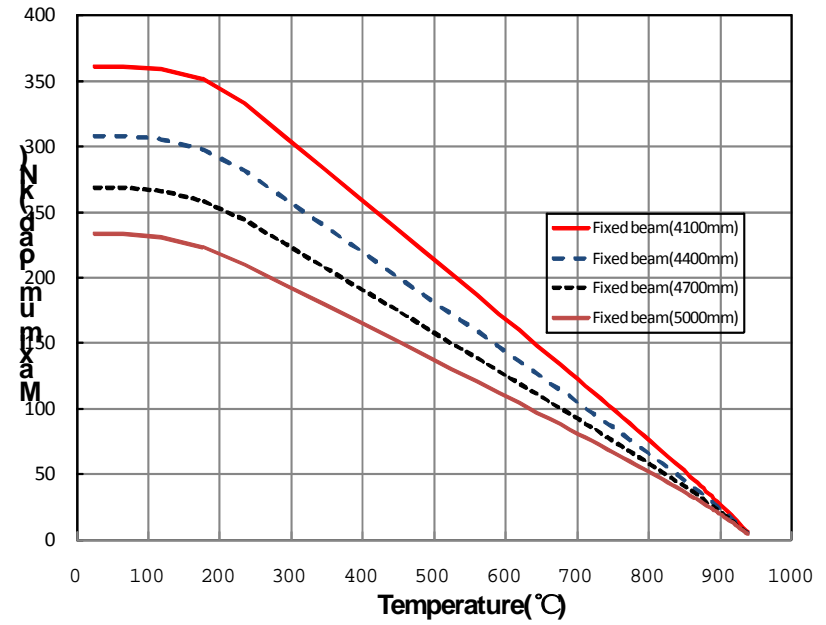

FIGURE III. MAXIMUM LOADS CHANGES ACCORDING TO SURFACE TEMPAERATURES(FIXED BEAM, SS 400)

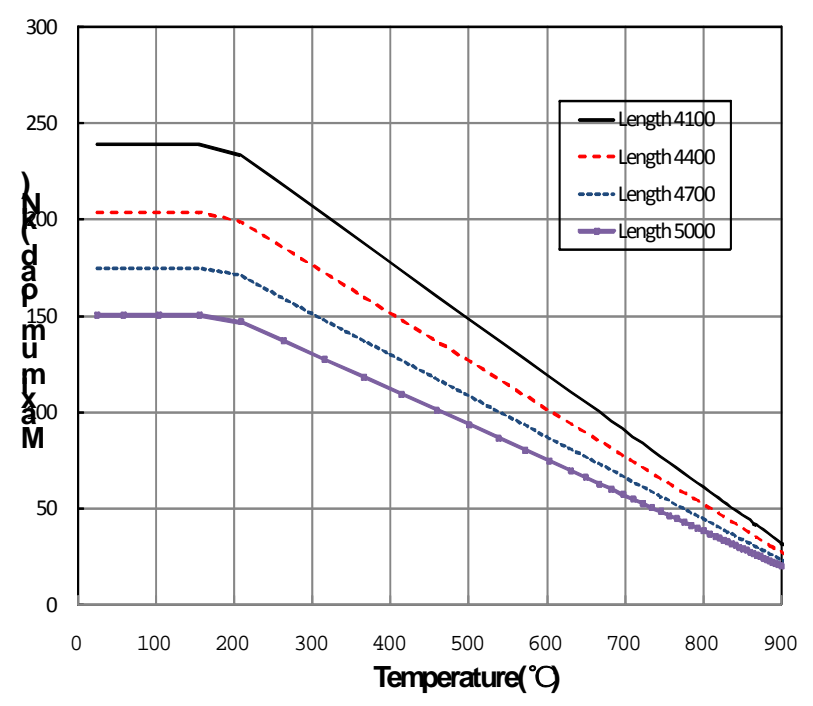

FIGURE IV. MAXIMUM LOADS CHANGES ACCORDING TO SURFACE TEMPAERATURES(SIMPLE BEAM, Sm 400)

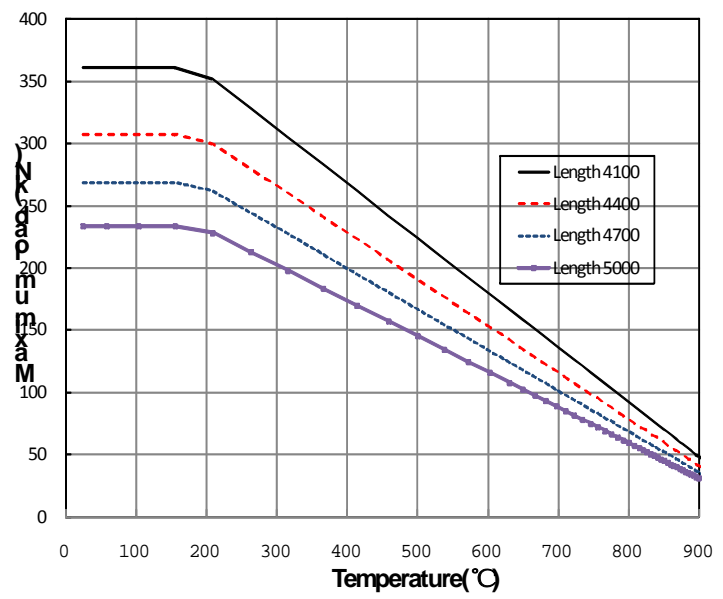

FIGURE V. MAXIMUM LOADS CHANGES ACCORDING TO SURFACE TEMPAERATURES(fixed BEAM, Sm 400)
Deflections according to each structural steel and boundary condition showed in Figure 6 to Figure 11 . Commonly, the deflections are going up according to increased surface temperatures. And the increasing ratios are higher as the lengths are longer. In case of fixed beam showed much lower deflections than those of simple beam.

Comparison of defections between SS 400 and SM 400 and boundary conditions are showed in Figure 10 to Figure 11. Deflections came from SM 400 showed a little lower than those from SS 400 up to range of $750^{\circ} \mathrm{C}$. Therefore, in terms of fire resistance the SM 400 is superior to SS 400 . But there is no big difference between SM 400 and SS 400 in structural stabilities in high temperatures.

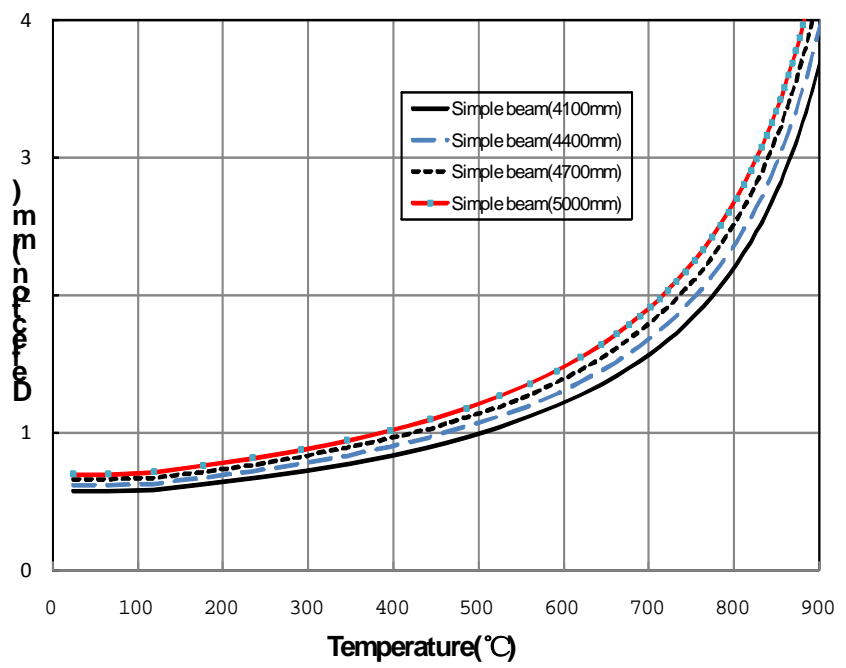

FIGURE VI. DEFLECTION histories ACCORDING TO SURFACE TEMPAERATURES(SIMPLE BEAM, SS 400)

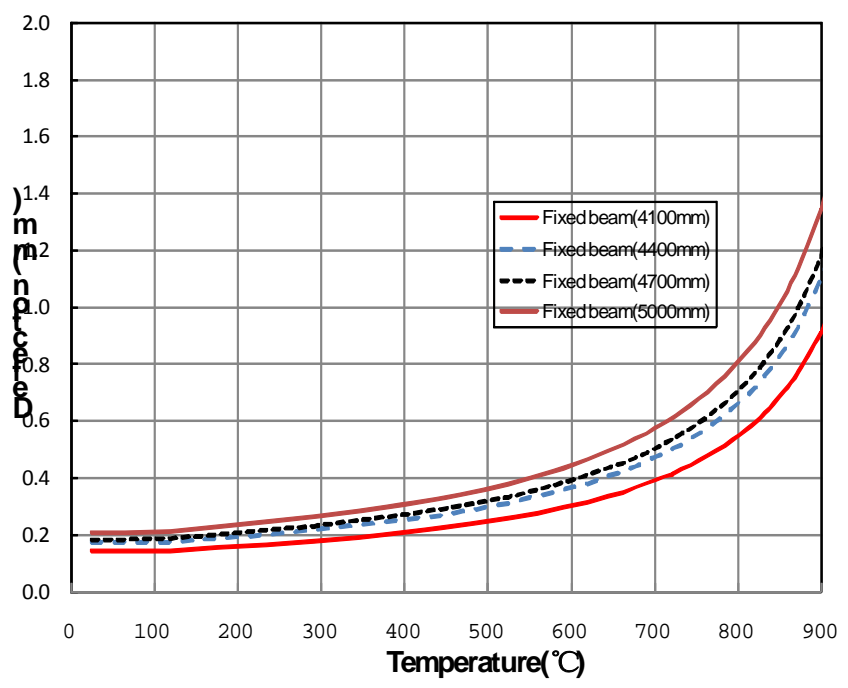

FIGURE VII. DEFLECTION histories ACCORDING TO SURFACE TEMPAERATURES(FIXED BEAM, SS 400) 


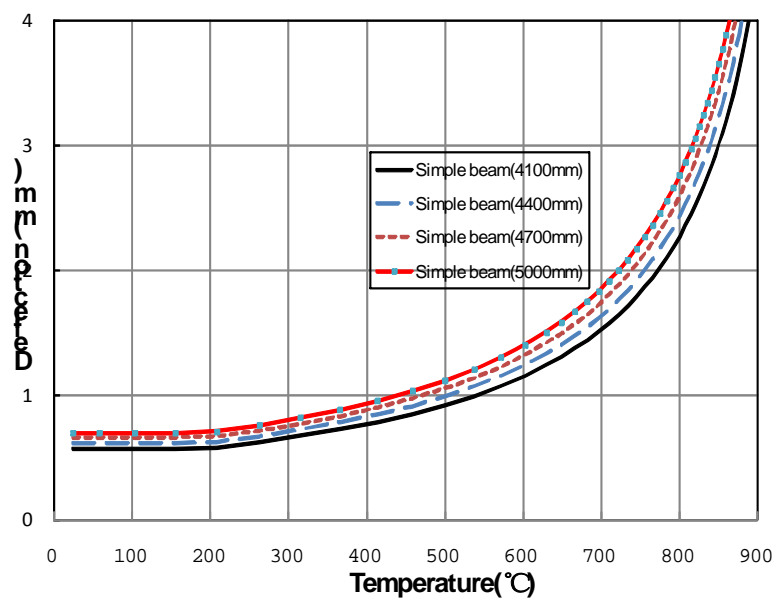

FIGURE VIII. DEFLECTION histories ACCORDING TO SURFACE TEMPAERATURES(SIMPLE BEAM, Sm 400)

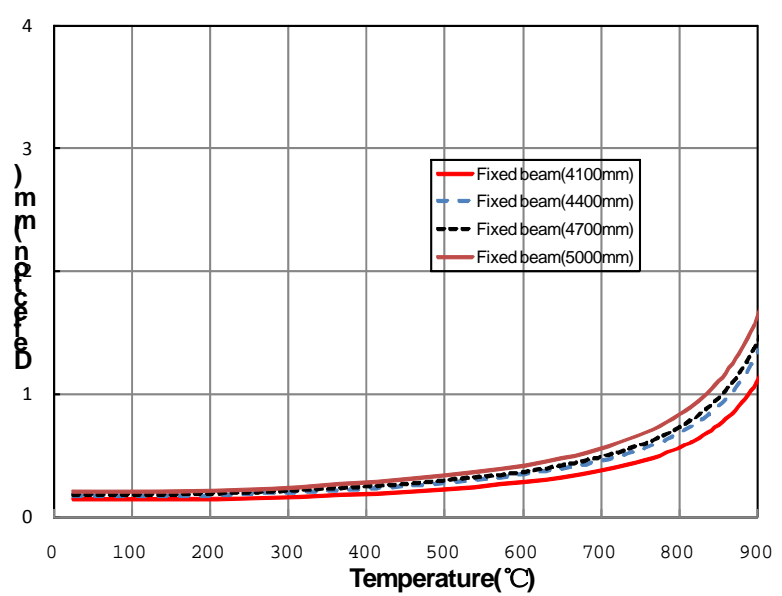

FIGURE IX. DEFLECTION HISTORIES ACCORDING TO SURFACE TEMPAERATURES(FIXED BEAM, SS 400)

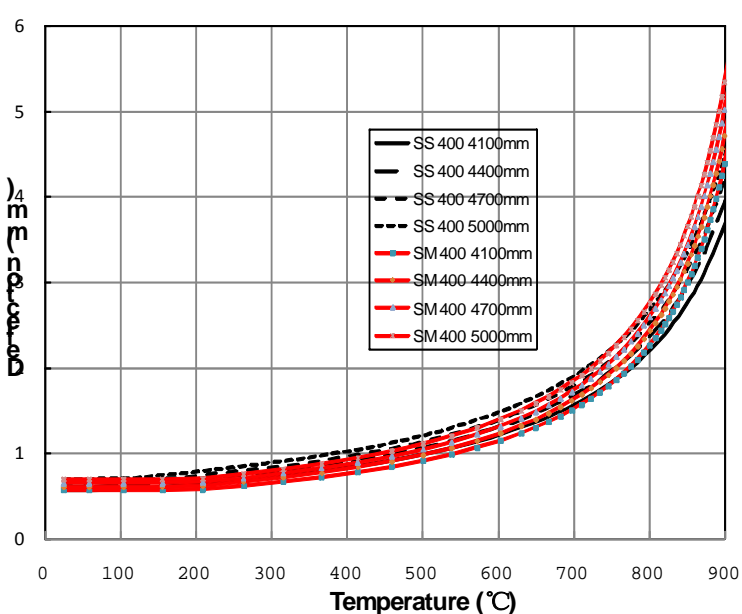

FIGURE X. DEFLECTION HISTORIES ACCORDING TO SURFACE TEMPAERATURES(SIMPLE BEAM, SS 400, SM400)

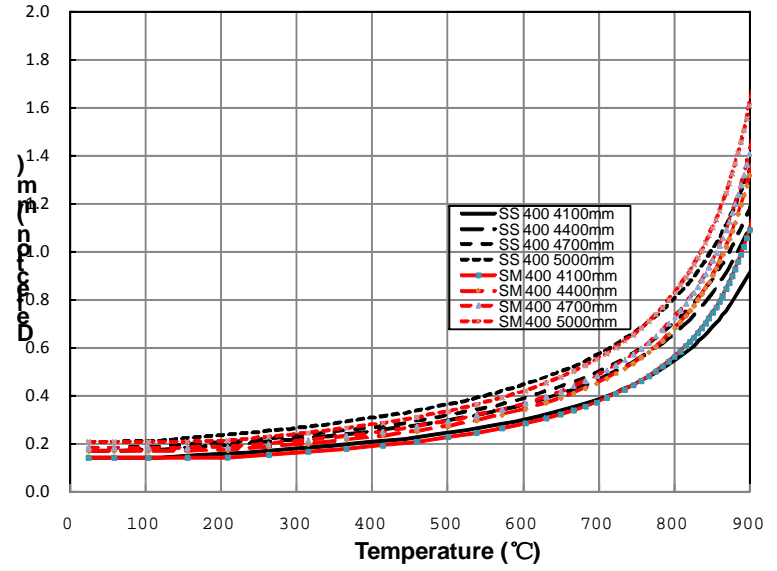

FIGURE XI. DEFLECTION histories ACCORDING TO SURFACE TEMPAERATURES(FIXED BEAM, SS 400, SM400)

\section{CONCLUSIONS}

In order to evaluate the fire resistance of long span beam built with SS 400 and SM 400, fire engineering method was used and found out the followings;

1) The maximum loads from each structural steel versus increasing surface temperature of beams are calculated.

2) Deflections from each structural steel versus increasing surface temperatures of beams are suggested.

3) The fire resistance performance of each structural steels are very clsed but up to range of $750^{\circ} \mathrm{C}$, the SM 400 showed better slightly than that of SS 400 .

\section{ACKNOWLEDGMENT}

This work was supported by the Nuclear Research \& Development of the Korea Institute of Energy Technology and Planning (KETEP) grant funded by the Korea government Ministry of Trade Industry and Energy. (No.20151510101780).

\section{REFERENCES}

[1] C. R. Barnett, G. C. Clifton, Examples of fire engineering design for steel members, using a standard fire curve versus a new parametric curve, Fire and Materials, 28, pp.309-322 (2004).

[2] Korean Standard Association, KS B 0802, Method of tensile test for metallic materials, Seoul, Korea (2003).

[3] Korean Standard Association, KS D 0026Method of elevated temperature tensile test for steels and heat-resisting alloys, Seoul, Korea (2002).

[4] D. C. Jang, S. H. Jang, "Solution of Architectural Structural Dynamic", Seoul, Korea (2005).

[5] I. K. Kwon, "Analytic Study of Structural Stability at High Temperature of Structural Beam Made of SM 400", Advanced Materials Research, Vol. 977, pp. 378-381 (2014). 